\title{
Measurement of seagrass standing crop using satellite and digital airborne remote sensing
}

\author{
P. J. Mumby ${ }^{1, *}$, E. P. Green ${ }^{2}$, A. J. Edwards ${ }^{2}$, C. D. Clark ${ }^{1}$ \\ ${ }^{1}$ Sheffield Centre for Earth Observation Science and Department of Geography, University of Sheffield, Winter Street, \\ Sheffield S10 2TN, United Kingdom \\ ${ }^{2}$ Centre for Tropical Coastal Management Studies, Department of Marine Sciences and Coastal Management, \\ Ridley Building, University of Newcastle, Newcastle upon Tyne NE1 7RU, United Kingdom
}

\begin{abstract}
The standing crop of seagrass is highly sensitive to environmental disturbance. We evaluate 3 optical remote sensing methods for measuring standing crop in the tropical Western Atlantic. Extensive field measurements of standing crop were used to define empirical relationships with imagery from satellite sensors [Landsat Thematic Mapper and SPOT (Système Probatoire de l'Observation de la Terre) XS (multispectral)], and the digital airborne imager CASI [Compact Airborne Spectrographic Imager). Predictions of standing crop from processed imagery had high coefficients of determination: $0.74,0.79$ and 0.81 respectively. Using a bootstrap method to measure standard error, the $95 \%$ confidence interval of predictions was found to have a similar order of magnitude to quadrat sampling in situ at a precision (standard error/mean) of 10\%. Explicit cost-benefit and monitoring considerations are discussed.
\end{abstract}

KEY WORDS: Seagrass standing crop Remote sensing · CASI · Monitoring

\section{INTRODUCTION}

Ecologists and managers of seagrass systems require a suite of data on the status of seagrass habitats (for an overview see Phillips \& McRoy 1990). Remote sensing provides a synoptic assessment of seagrass and several parameters have been measured. Seagrass boundaries have been mapped extensively with conventional aerial photography (Kirkman et al. 1988, Ferguson et al. 1993, Sheppard et al. 1995) and, by showing the location and extent of seagrass habitat, they may be indicative of the health of coastal systems (Dennison et al. 1993). Similarly, SPOT (Système Probatoire de l'Observation de la Terre) XS (multispectral) imagery has been used to highlight the seagrass die-off in Florida Bay, USA (Robblee et al. 1991). Seagrass cover has been mapped semi-quantitatively using an airborne multispectral scanner (Savastano et al. 1984) and the satellite sensors Landsat Thematic Mapper (Luczkovich et al. 1993, Zainal et al. 1993) and SPOT XS (Cuq 1993). A more detailed study in the Bahamas ob-

•E-mail:p.j.mumby@sheffield.ac.uk tained a quantitative empirical relationship between Landsat TM and seagrass biomass (Armstrong 1993). The most ambitious goal for remote sensing of seagrass has been determination of species composition. However, recent evidence suggests that this goal is unlikely to be realised because spectral sensors lack the sensitivity to distinguish the spectra of different species (Jernakoff \& Hick 1994).

Given that a variety of remote sensing methods exist, it is perhaps surprising that comparative assessments are scarce. Until different satellite and airborne methods are rigorously compared, it will remain difficult for the practitioner to make an informed selection of methods. We have compared the performance of various remote sensing platforms for mapping coral, mangrove and seagrass habitats of the Caicos Bank, British West Indies (Green et al. 1997a, b, Mumby et al. 1997c). This evaluation incorporated the high-resolution digital airborne instrument CASI (Compact Airborne Spectrographic Imager) which currently represents the state of the art in optical remote sensing. Mumby et al. (1997d) found that the delineation of seagrass beds was significantly more accurate using CASI than satellite sensors 
and conventional means of colour aerial photography. The present study aims to extend this evaluation to the quantitative mapping of seagrass standing crop. Standing crop is a useful parameter to measure because it responds promptly to environmental disturbance and changes are usually large enough to monitor (Kirkman 1996).

This study builds on the work of Armstrong (1993) and, in so doing, we present a rigorous approach to empirical regression modelling and outline how the statistical confidence in standing crop predictions can be incorporated explicitly into a monitoring programme.

There are 2 methods of predicting a parameter of interest (standing crop) from optical remote sensing First, an empirical relationship can be sought between the parameter and image data. This is the most common approach and is explored here. Its usual shortcoming, however, is a failure to explain why the empirical relationship exists. The second approach is to develop a radiative transfer model and make predictions from first principles (e.g. Plummer et al. 1997). In reality, these approaches are complementary. An empirical relationship must exist for a radiative-transfer model to be of use, whilst in the absence of a model, the limitations of the empirical approach are difficult to ascertain. This study represents the empirical component of a dual approach to mapping seagrass standing crop. Empirical relationships between seagrass standing crop and the sensors Landsat TM, SPOT XS and CASI are quantified and discussed in the context of monitoring programmes.

\section{METHODS}

Study site and imagery. Studies were conducted around the island of South Caicos, Turks and Caicos Islands (British West Indies). Seagrass was located in shallow $(<10 \mathrm{~m}$ deep) clear water (horizontal Secchi distance 20 to $50 \mathrm{~m}$ ) and was dominated by the species Syringodium filiforme (Kützing) and Thalassia testudinum (Banks ex König). CASI imagery was obtained in July 1995 for an area exceeding 100 ha. The CASI was configured to record data at high spatial resolution $(1 \mathrm{~m})$ and in 8 spectral bands. Five of these bands were designated in the region of the electromagnetic spectrum which best penetrates water (ca 400 to $650 \mathrm{~nm}$ ). The remaining 3 bands encompassed red and near infrared wavelengths for the purposes of assessing nearshore mangrove (Green et al. $1997 \mathrm{~b})$ and are not discussed further here. For further details see Fig. 1 and Clark et al. (1997).

SPOT XS imagery was acquired in March 1995. In 1995, the most recent Landsat TM image of the Turks and Caicos Islands with less than 10\% cloud cover had been acquired in November 1990. The spatial resolutions of SPOT XS and Landsat TM were 20 and $30 \mathrm{~m}$ respectively.

Field sampling. Field data were gathered in July and August 1995. Seagrass standing crop was sampled using a visual assessment method (Mumby et al. 1997 b). Standing crop was categorised into a 6 point linear scale using $0.25 \mathrm{~m}^{2}$ quadrats. The scale was calibrated before and after the field survey by measuring epiphyte-free dry weights of seagrass from 103 reference quadrats. The field survey encompassed 120 sites with 6 visual estimates of standing crop per site. Such extensive sampling would not have been possible using destructive quadrat sampling (Downing \& Anderson 1985) because the processing time alone would exceed 100 survey days (at $7 \mathrm{~h}$ per day).

All sites were located using a differential global positioning system (DGPS) with 2 to $5 \mathrm{~m}$ circle error probable (Trimble Navigation Ltd 1993). Given this locational uncertainty, the minimum seagrass area sampled was a circle of 5 to $10 \mathrm{~m}$ diameter.

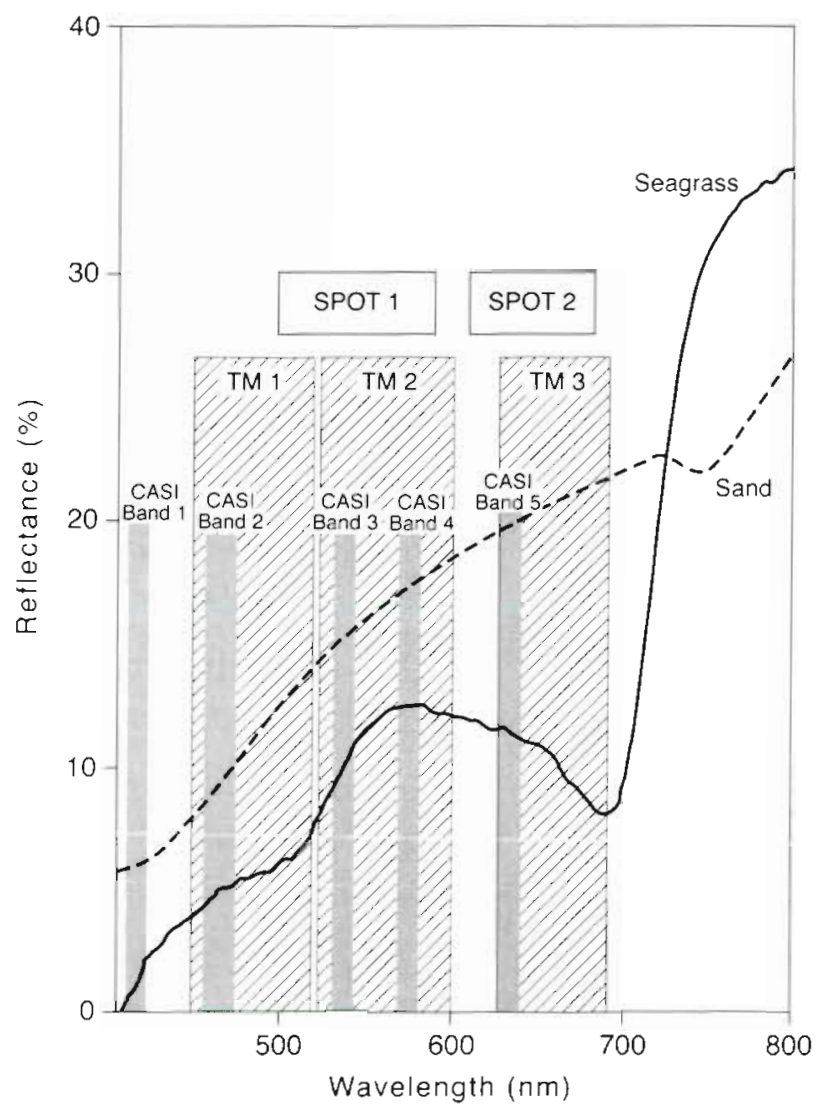

Fig. 1. Spectral profile of sand and the seagrass Thalassia testudinum (epiphytes present) in relation to the spectral bands of remote sensing instruments. Spectral profile redrawn from Armstrong (1993). Figure can only act as a guide to interpreting seagrass spectra because the species Syringodium fillforme is not included 
Image processing. All imagery was geo-coded to UK Ordnance Survey maps (series E8112 DOS 309P). Satellite images were radiometrically and atmospherically corrected following the methods of Price (1987) and Tanre et al. (1990). CASI data were radiometrically corrected using an aircraft-mounted incident light sensor which recorded downwelling incident irradiance

The confounding influence of variable water depth on bottom reflectance was ameliorated using the method of Lyzenga $(1978,1981)$. This method creates a single depth-invariant bottom index from each pair of spectral bands (for further details, see Mumby et al. 1997a). A single bottom index was obtained for SPOT XS (from bands 1 and 2, denoted b1_b2), 3 indices were created from Landsat TM bands 1, 2 and 3 (i.e. b1_b2, b1_b3, b2_b3) and 6 indices were created from CASI bands 1 to 5 . We stress the importance of this processing step by noting that the coefficient of determination for seagrass standing crop regressed on reflectance (not corrected for depth) ranged from 0.15 to 0.51 (Landsat TM), 0.05 to 0.32 (SPOT XS) and 0.01 to 0.21 (CASI). These values were considered too low for adequate prediction of seagrass standing crop.

Where more than 1 depth-invariant bottom index was available for a sensor (i.e. for Landsat TM and CASI), principal component analyses were carried out to combine multiple indices into a single regressor index (the first principal component).

Statistical methods. The strength of the relationship between remotely sensed image parameters (bottom indices and first principal components) and seagrass standing crop was determined using parametric correlation. Tests for significant differences between correlations (e.g. between different bottom indices) were carried out using the methods of Zar (1996, p. 380).

The degree to which remotely sensed imagery could predict seagrass standing crop was determined using model I linear regression. The confidence (error) of this procedure can be determined by testing the degree to which the regression equation correctly predicts the standing crop of an independent (accuracy) data set. Note that these confidence levels differ to the default confidence zones plotted around a regression line by most statistical software. These latter zones are based on the regressor data and do not provide an independent estimate of confidence. Therefore, they should not be used to assess the confidence of predictions from the regression equation. However, care must be taken when using an independent accuracy data set. The coefficient of determination $\left(\mathrm{r}^{2}\right)$ is highly sensitive to the distribution of data about the least squares regression and is strongly influenced by the choice of regressor data and independent accuracy data. In short, a single regression may not be particularly representative of the data set. In light of this issue, boot- strap methods (Bradley \& Tibshirani 1993) were invoked to provide a better estimate of the standard error and hence the $95 \%$ confidence levels of the predictions.

Standing crop data were transformed to fit a linear regression against image data. Several transformations were attempted (e.g. square root and $\log _{10}$ ) and the transformation which gave the highest $r^{2}$ was selected. For each image type, field data were randomly assigned to 1 of 2 groups: regressor data ( $60 \%$ of the full data set) or accuracy data $(40 \%$ of the data set). The regressor data were used to derive a regression equation for standing crop and image data. This equation was then used to predict the standing crop $(Y)$ for each independent (accuracy) point $\left(Y_{0}, X_{0}\right)$. This process yielded a single measure of $\mathrm{r}^{2}$ and allowed the difference between predicted $(Y)$ and measured $\left(Y_{0}\right)$ standing crop to be calculated for each of the accuracy data $\left(X_{0}\right)$. The process was then repeated but the regressor and accuracy data were re-selected at random from the full data set. In total, this process was repeated 50 times for CASI data (full data set, $\mathrm{n}=33$ ) and 30 times for both SPOT XS $(n=110)$ and Landsat TM ( $n=83$ ). The mean difference between predicted $(Y)$ and field-determined $\left(Y_{0}\right)$ values was used to determine the standard error (SE) about the regression at each value of $X_{0}$ (bottom index).

followed by

$$
\text { SE of } Y_{0}=\sqrt{\frac{\left(Y-Y_{0}\right)^{2}}{n}}
$$

$$
\begin{gathered}
95 \% \text { confidence } \\
\text { level of } Y_{0}
\end{gathered}=Y_{0} \pm\left(\mathrm{SE} \text { of } Y_{0}\right) \times t_{(0.05)(2) \mathrm{df}(n-2)}
$$

where $t=$ critical value of the $t$ distribution (Zar 1996) and $n=$ number of samples of $\left(Y-Y_{0}\right)$ for each value of $X_{0}$.

The regression equation which best explained variation in standing crop (i.e. highest $r^{2}$ ) was selected to create a single calibration curve. The $95 \%$ confidence levels (CLs) about this curve were fitted using the equations given above. Note that the magnitude of each $C L$ is dependent on the accuracy of prediction (i.e. magnitude of $Y-Y_{0}$ ) and the number of measurements of $\left(Y-Y_{0}\right)$ for each value of $X_{0}$. If the field data are concentrated around particular values of $X_{0}$, the CL may be proportionately smaller than elsewhere. Ideally, field data should represent the range of $X_{0}, Y_{0}$ as evenly as possible.

\section{RESULTS}

\section{Predicting standing crop using satellite imagery}

SPOT XS. The bottom index from SPOT XS was strongly correlated to seagrass standing crop (Pearson 
product-moment correlation coefficient, $\mathrm{r}=0.83, \mathrm{n}=$ 110). Regression of seagrass standing crop on image data yielded a maximum coefficient of determination $\left(\mathrm{r}^{2}\right)$ of 0.79 and a minimum of 0.59 (mean 0.69). The regression equation with an $r^{2}$ of $0.79(p<0.0001)$ was

\section{Seagrass standing $\operatorname{crop}\left(\mathrm{g} \mathrm{m}^{-2}\right)=$}

$[38.6-(5.6 \times \text { image data })]^{2}$

where 'image data' refers to the depth-invariant bottom index.

The $95 \%$ CLs about this regression line are shown in Fig. 2. When interpreting this figure, it should be borne in mind that the $y$-axis has been square root transformed and that, in absolute terms, the 95\% CLs are symmetrical about the regression line. However, this pattern does not hold at very low standing crops $1<2 \mathrm{~g}$ $\mathrm{m}^{-2}$ ) where the $95 \%$ confidence interval is asymmetric because seagrass standing crop of $<1 \mathrm{~g} \mathrm{~m}^{-2}$ could not be measured. The data set was skewed toward lower standing crop and this reduced the size of CLs in this region because the standard error and critical $t$-values used to calculate each CL contained $n$ as the denominator. In addition, the variability among CLs was greater at higher standing crops where data were less concentrated (see 'Methods').

Landsat TM. The correlation between seagrass standing crop and Landsat TM data was similar to that from SPOT XS. Two of the 3 bottom indices (b1_b2 and b1_b3) had a correlation of 0.80 and the third (b2_b3) achieved 0.71 The first principal component of all 3 bands explained $92 \%$ of their variance and had a correlation of 0.78 with seagrass standing crop. However, neither of the correlations differed significantly $(\alpha=$ $0.05, \mathrm{n}=83$ ).
Since principal component analysis constituted further image processing effort without conveying a significant correlatory advantage, it was not used for predicting seagrass standing crop. Regression of standing crop onto b1_b2 (image data) produced a wide range of $r^{2}(0.18$ to 0.74 ; mean 0.56$)$ but the optimum equation is plotted in Fig. 3 and described below.

\section{Seagrass standing crop $\left(\mathrm{g} \mathrm{m}^{-2}\right)=$ $[11.5-(7.41 \times \text { image data })]^{2}$ \\ Predicting standing crop using high resolution airborne CASI imagery}

Heuristic correlation analysis of all bottom indices with seagrass standing crop found that the highest correlations were achieved from indices derived from spectral band numbers b3_b4, b1_b5, b2_b5, b3_b5 and b4_b5 (correlations $0.76,0.77,0.81,0.83,0.79$ respectively). The correlations between these bands did not differ significantly from each other (Table 1) but some were significantly better correlated than other bands (e.g. b1_b4, b1_b3) which were discarded from further analysis. The first principal component of the indices explained $94 \%$ of their variance and achieved a correlation of 0.83 with standing crop.

For the reasons given above, the first principal component was not used to predict seagrass standing crop. Fig. 4 presents a regression relationship for the bottom index derived from CASI bands 3 and 5 (denoted b3_b5). The regression had an $\mathrm{r}^{2}$ of 0.81 (minimum 0.51 ; mean 0.68 ) and the following equation:

Seagrass standing crop $\left(\mathrm{g} \mathrm{m}^{-2}\right)=10^{636-(146 \times \text { image data })}$

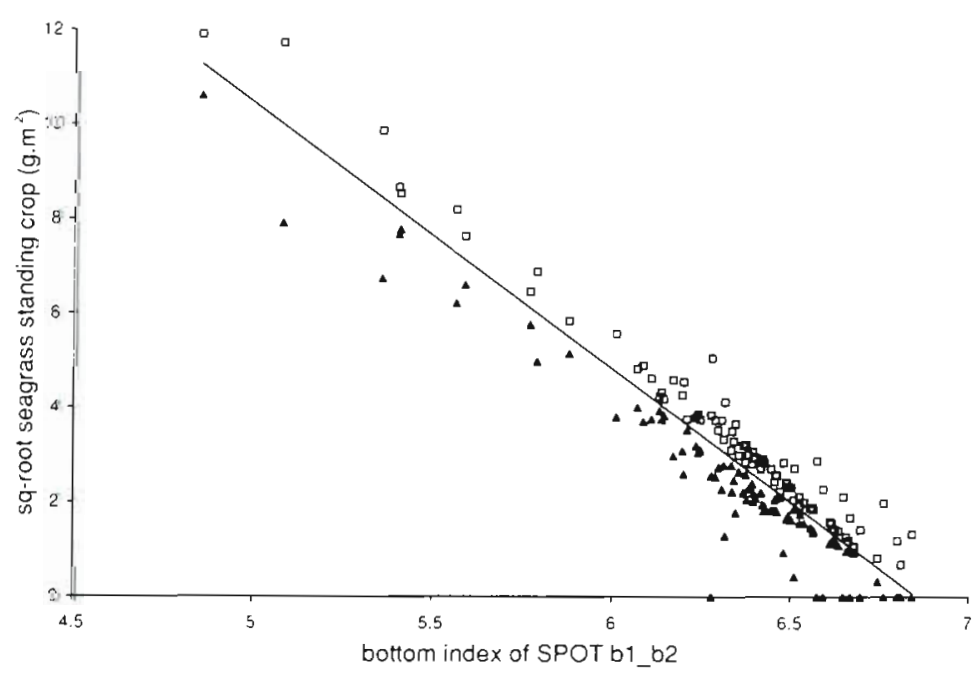

Fig. 2. Regression of processed SPOT XS data on seagrass standing crop showing upper $(\square)$ and lower ( $\Delta$ ) $95 \%$ confidence levels

\section{Comparison of remote sensing methods and quadrat sampling for estimating seagrass standing crop}

The strength of correlations between image data and standing crop did not differ significantly from sensor to sensor (Table 2).

To examine how $95 \%$ CLs differed between seagrass beds, 5 levels of standing crop were selected based on categories 2 to 6 of the sampling scale (Mumby et al. 1997b). The range of standing crop within each category (Fig. 5) was used to select corresponding CLs from the regression analyses. The mean of the CLs was then expressed as a percentage of the mean standing crop of each category (Fig. 5). Since this entailed unequal sample sizes, Fig. 5 is intended to illustrate trends rather than permit hypothesis testing. 


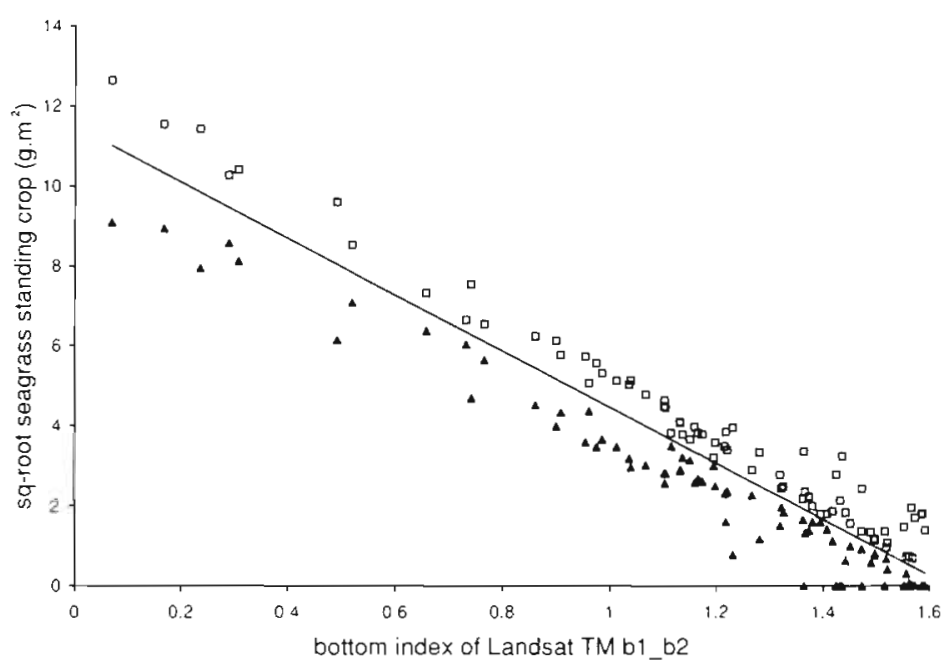

Fig. 3. Regression of processed Landsat TM data (b1_b2) on seagrass standing crop showing upper $(\square)$ and lower $(\Delta)$ 95\% confidence levels

The $95 \%$ CL of standing crop prediction from CASI became proportionately smaller as the standing crop of seagrass increased. This trend was not evident for SPOT XS because the high concentration of field data of low standing crop confounded interpretation: prediction of low standing crop was made relatively accurately. The spread of field data for Landsat TM was less skewed and showed a similar trend (though less marked) to CASI imagery.

Table 1. Comparison of the correlation between seagrass standing crop and different bottom indices of CASI. b1 b2 and b1_b3 have the same correlation and are used interchangeably. ns: not significant $(\alpha=0.05, \mathrm{n}=33)_{i}{ }^{\prime} \mathrm{p}<0.05, \cdots p<$ 0.01 . Details of test are given in Zar (1996)

\begin{tabular}{|c|c|c|c|c|c|c|c|}
\hline \multicolumn{2}{|c|}{ Bottom index } & \multicolumn{2}{|c|}{ Correlations } & \multicolumn{2}{|c|}{$z$-transformation } & \multirow{2}{*}{$\begin{array}{c}\text { Test } \\
\text { statistic Z }\end{array}$} & \multirow{2}{*}{$\begin{array}{c}\text { Significance } \\
\text { of test }\end{array}$} \\
\hline Index $x_{1}$ & Index $_{2}$ & $\mathrm{r}_{1}$ & $r_{2}$ & $z_{1}$ & $z_{2}$ & & \\
\hline b1_b4 & b3_b5 & 0.37 & 0.83 & 0.38 & 1.18 & 3.09 & . \\
\hline b2_b5 & b3_b5 & 0.81 & 0.83 & 1.12 & 1.18 & 0.23 & ns \\
\hline b3_b4 & b3_b5 & 0.76 & 0.83 & 0.99 & 1.18 & 0.73 & ns \\
\hline b2_b3 & b3_b5 & 0.47 & 0.83 & 0.51 & 1.18 & 2.59 & $\because$ \\
\hline b2_b4 & b3_b5 & 0.58 & 0.83 & 0.66 & 1.18 & 1.64 & ns \\
\hline b1_b3 & b4_b5 & 0.39 & 0.79 & 0.41 & 1.07 & 2.55 & $\cdot$ \\
\hline $\mathrm{b} 2 \mathrm{~b} 4$ & $b 2 \_b 5$ & 0.58 & 0.81 & 0.66 & 1.12 & 1.78 & ns \\
\hline
\end{tabular}

Measurement of seagrass standing crop with the remote sensing methods described here compared favourably to quadrat harvest (Fig 5). At low standing crop, quadrat harvest provided greater confidence although this was of the same order of magnitude as that achieved from remote sensing. Remote sensing and field sampling had comparable confidence levels for seagrass beds of medium standing crop, and remote sensing generally out-performed quadrat harvest in areas of high standing crop. Clearly, this observation is dependent on the precision to which quadrat sampling is conducted. The data presented in Fig. 5 assumed that a sampling precision (ratio of standard error to mean) of 0.1 was specified for all seagrass beds (see Downing \& Anderson 1985). The estimates for quadrat sample size and confidence were based on calibration data from Mumby et al. (1997b).

\section{DISCUSSION}

\section{Performance of bottom indices and spectral considerations}

The first principal components of Landsat TM and CASI bottom indices did not convey any significant correlatory advantage. Although this result was surprising in principle, we attribute it to the high correlation of component indices which, when combined, failed to offer improved information. This explanation was borne out by the high degree of variance explained by the first principal components 192 and $94 \%$ for Landsat TM and CASI respectively).

With appropriate processing for water column effects, all 3 image types predicted seagrass standing crop with a $95 \%$ confidence interval that ranged from approximately 5 to $80 \mathrm{~g} \mathrm{~m}^{-2}$ per calibration. For each pair

Table 2. Comparison of the correlation between seagrass standing crop and different image types. Where appropriate, the best correlations were used for each image type (i.e. b1_b2 or b1_b3 for Landsat TM and b3_b5 for CASI). ns: not significant

\begin{tabular}{|c|c|c|c|c|c|c|c|c|c|}
\hline \multicolumn{2}{|c|}{ Sensor } & \multicolumn{2}{|c|}{ Correlations } & \multicolumn{2}{|c|}{ Samples } & \multicolumn{2}{|c|}{$z$-transformation } & \multirow{2}{*}{$\begin{array}{c}\text { Test } \\
\text { statistic Z }\end{array}$} & \multirow{2}{*}{$\begin{array}{c}\text { Significance } \\
\text { of test }\end{array}$} \\
\hline Sensor $_{1}$ & Sensor $_{2}$ & $r_{1}$ & $\mathrm{r}_{2}$ & $\mathrm{n}_{1}$ & $\mathrm{n}_{2}$ & $z_{1}$ & $z_{2}$ & & \\
\hline CASI & SPOT XS & 0.83 & 0.83 & 33 & 110 & 1.18 & 1.18 & 0.00 & ns \\
\hline CASI & Landsat TM & 0.83 & 0.80 & 33 & 83 & 1.18 & 1.09 & 0.42 & ns \\
\hline SPOT XS & Landsat TM & 0.83 & 0.80 & 110 & 83 & 1.18 & 1.09 & 0.61 & ns \\
\hline
\end{tabular}




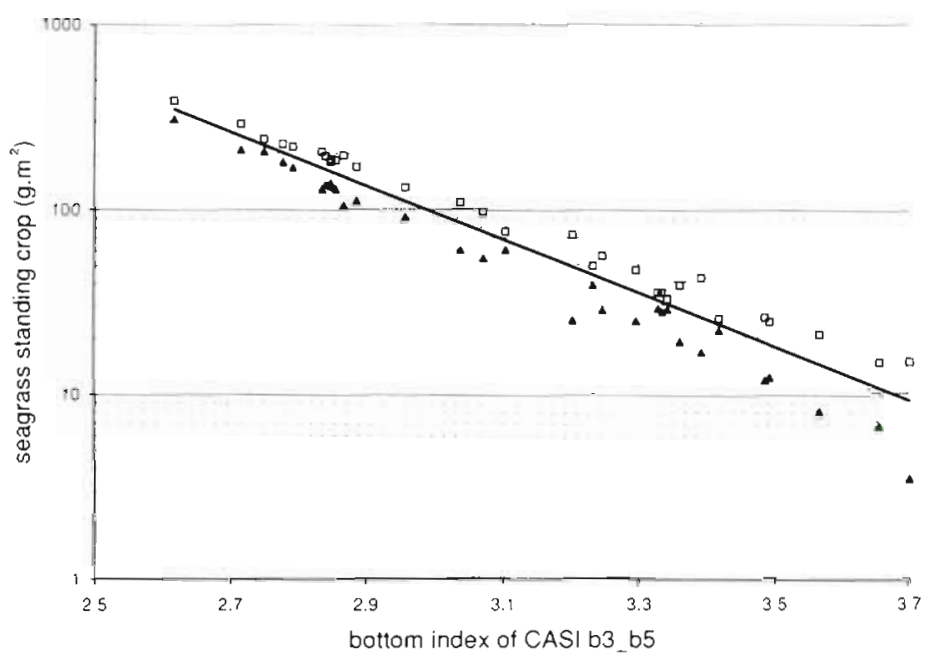

Fig. 4. Regression of processed CASI data (b3_b5) on seagrass standing crop showing upper ( $\square$ ) and lower ( 4 ) $95 \%$ confidence levels

of spectral bands, the bottom index developed by Lyzenga $(1978,1981)$ distinguishes bottom types according to the difference between their reflectance characteristics and those of sand. Comparison of Armstrong's (1993) reflectance profiles for sand and seagrass in the Bahamas (Fig. 1) shows that CASI bands 1 , 2, 3 and 4 have similar trends (i.e. the profiles are almost parallel and relatively closely correlated). Because of the high degree of correlation, bottom

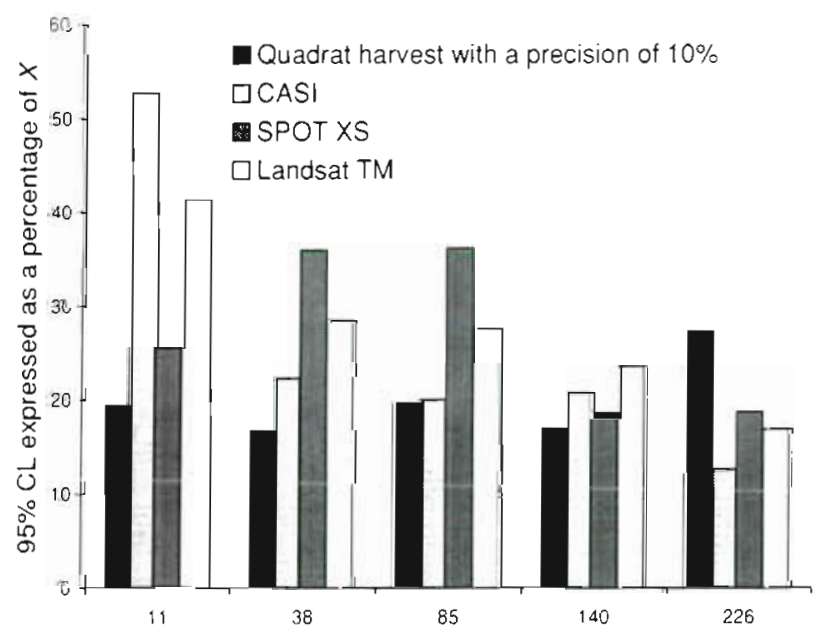

(X) Approx. standing crop of seagrass bed $\left(\mathrm{g} \cdot \mathrm{m}^{2}\right)$

Fig. 5. Comparison of $95 \%$ CLs expressed as a proportion of the mean standing crop of seagrass. $95 \%$ CLs for remote sensing were determined from results of the bootstrap procedure (see text). 95\% CLs for quadrat sampling were determined from field data published in Mumby et al. (1997b). The mean and range $\left(\mathrm{g} \mathrm{m}^{-2}\right)$ of each standing crop category are 11 ( 4 to 21$), 38$ (22 to 67 ), 85 (43 to 134 ), 140 (96 to 200), and 226 (170 to 299 ). The number of quadrats required for a sampling precision of $10 \%$ is $20,11,12,3$ and 3 respectively indices derived from coupling any 2 of these bands would be expected to offer relatively poor discriminating power. With the exception of b3_b4, the results verified this expectation. The reason for the surprisingly good performance of b3 b4 is not entirely clear but it may be attributed to the relatively high reflectance of seagrass in these bands which allowed CASI to detect the differences in their sand-seagrass reflectance characteristics.

All indices which utilised band 5 correlated well with standing crop. This was probably due to the marked difference in reflectance characteristics between sand and seagrass in this band.

Of the Landsat TM bands, band 3 has the greatest difference in spectral response between sand and seagrass. Bottom indices derived from bands $1 \_3$ and 2_3 were therefore expected to exhibit the greatest discriminating power. However, this was not found to be the case and may be due to the poorer light transmission through water in band 3 - i.e. the satellite sensor may lack the radiometric sensitivity required to detect signals from band 3 in water deeper than about $5 \mathrm{~m}$.

Given the limited spectral envelope in which optical remote sensing of the benthos is possible (ca 400 to $650 \mathrm{~nm}$ ), it is not surprising that SPOT, Landsat and CASI performed similarly overall. Each sensor possesses at least 2 bands which allow discrimination of sand and seagrass (Fig. 1). However, given hindsight, we suggest that future airborne multispectral surveys of seagrass standing crop place greater emphasis on the 580 to $650 \mathrm{~nm}$ zone of the electromagnetic spectrum. In the present study, bands 1 and 2 may have been more beneficial if they had been located either side of band 5 where the separability of sand and seagrass spectra is greater. Although the spectra of sand and seagrass are also distinguishable at a wavelength of $700 \mathrm{~nm}$, remote sensing of seagrass would be constrained to extremely shallow water (e.g. $<1 \mathrm{~m}$ ) because of the high attenuation of electromagnetic radiation in water at this wavelength. Since seagrass extends to a depth of approximately $12 \mathrm{~m}$ at the study site, such a severe depth constraint would render the use of such long wavelengths ineffective.

\section{Performance of sensors and spatial considerations}

Remote sensing was well suited to mapping seagrass of medium to high standing crop. Accurate predictions of low standing crop were more difficult to make for 2 reasons. First, the spectrum of chlorophyll was less defined and more easily confused with sand (see Cuq 
1993). Second, visual inspection of CASI imagery showed that seagrass of the Caicos Bank tended to be patchier at lower standing crop (to conserve space, imagery is not shown here, but see Clark et al. 1997). Greater patchiness led to increased inter- and intra-pixel variation which, in turn, resulted in relatively large $95 \%$ CLs. The effect of greater patchiness was most pertinent to CASI because its spatial resolution was an order of magnitude finer than satellite sensors. On the other hand, satellite imagery might be expected to smooth out much of the small-scale patchiness in standing crop. A fuller treatment of standing crop heterogeneity is beyond the scope of the present study and ecological inferences from this work will be reported at a later date (for example, examining the structure of seagrass blow-outs illustrated in Fig. 6).

\section{Limitations of this study and remote sensing in general}

The satellite-based elements of this study are potentially limited by the disparity in dates of field survey and image acquisition: an empirical calibration can only be expected to give reliable absolute values if these dates are similar. When a temporal disparity exists, the calibration is affected by seagrass dynamics. If the relative standing crop of calibration sites has not changed (e.g. due to a uniform decline in biomass with season), a good empirical relationship between image data and standing crop would be expected. However, the absolute values of the calibration may be offset too high or too low. This scenario may have applied to the SPOT XS image which was acquired 4 mo before field data were obtained. This is
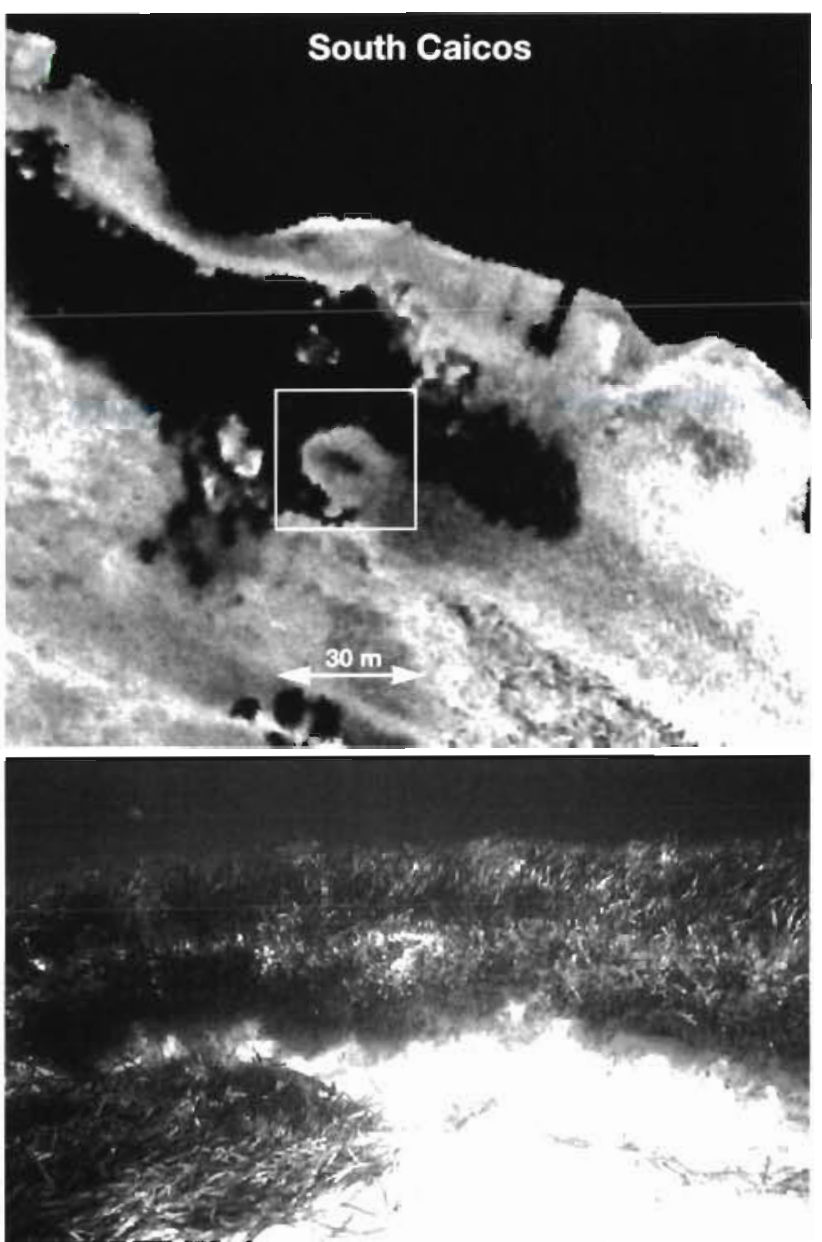

Fig. 6. The structure of a seagrass blow-out near South Caicos, British West Indies, showing CASI imagery (top), the appearance of the blow-out in situ (middle) and the predicted standing crop derived from CASI data (bottom). The CASI imagery constitutes an area of approximately $400 \mathrm{~m}^{2}$ and land has been masked out

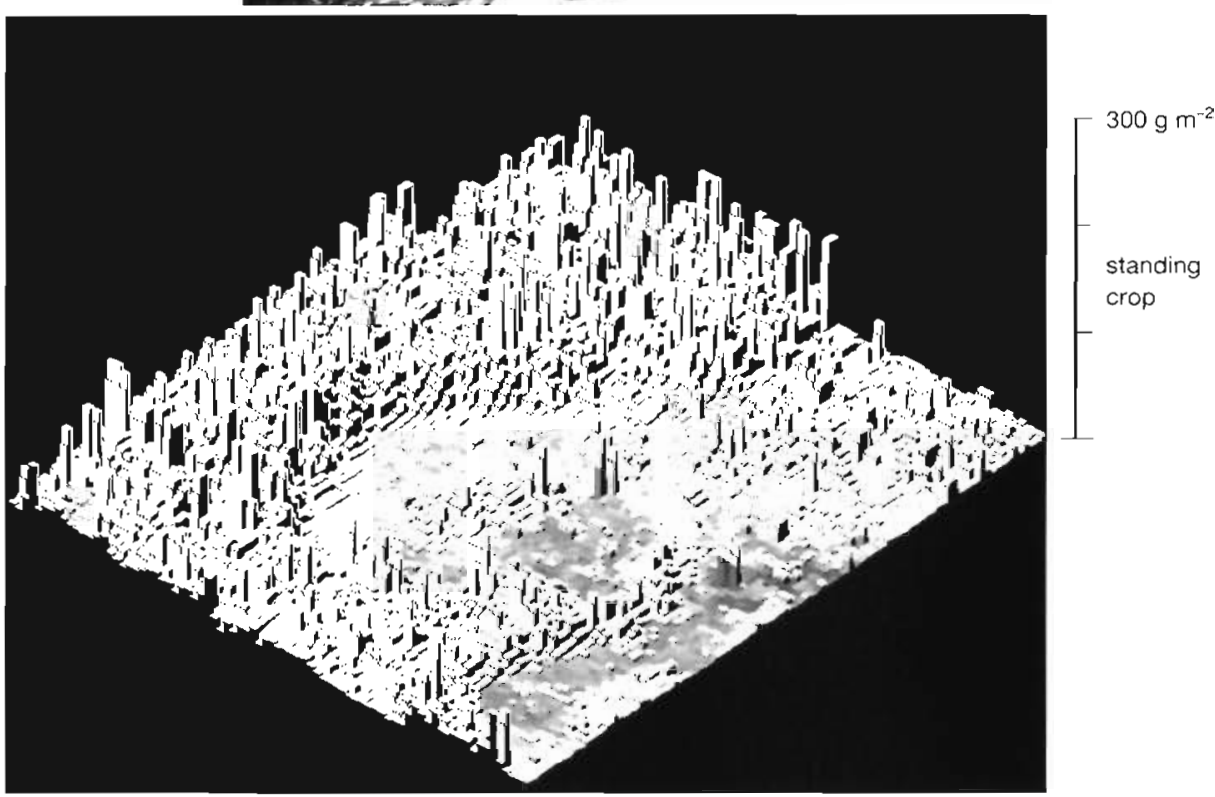


unlikely to be problematical where the objective is to map the pattern of standing crop.

A greater problem would be encountered if the spatial distribution of biomass changed between field survey and imagery acquisition. Under these circumstances, a proportion of the calibration sites would be misleading, resulting in poor calibration.

The calibration of Landsat TM imagery may have been confounded by this effect as the intervening period between field work and imagery acquisition was almost $5 \mathrm{yr}$. If confounding had occurred, the effect would have been partly mitigated by the coarse spatial resolution of the sensor $(30 \mathrm{~m})$ which is the least sensitive to changes in the spatial distribution of standing crop. The results presented for Landsat TM are best thought of as conservative; had more recent imagery been available, the calibration may have improved.

Although this study focuses on mapping the standing crop of seagrass, the extent of seagrass beds must be defined first. Mapping seagrass boundaries can be problematical, especially where seagrass is spectrally confused with other habitats such as areas of macroalgae, detritus or coral (Ferguson et al. 1993, Kirkman 1996). A key advantage of CASI over other remote sensing systems is its ability to map macroalgal and coral habitats with significantly greater accuracy than either satellite imagery or 1:10000 colour aerial photography (Mumby et al. 1997d). For example, beds of the phaeophyte Lobophora variegata were mapped with an accuracy of $82 \%$ with CASI imagery and less than $40 \%$ with Landsat TM, SPOT XS and aerial photography. If satellite imagery or aerial photography is used to map seagrass and an accuracy of $<40 \%$ is inadequate, the locations of seagrass boundaries should be verified in situ for each area of interest.

Possibly the main limiting circumstances for optical remote sensing of standing crop are cloud cover (particularly for satellite imagery), turbid water and deep water (Green et al. 1996). Excessive cloud cover in a region will reduce the chance of obtaining suitable imagery, and severe light attenuation in deep and turbid water can make optical remote sensing inappropriate. Under such circumstances, acoustic (Sabol et al. 1997) or videographic (Norris et al. in press) remote sensing methods are preferable although both are currently under development.

\section{Selection of methods for mapping and monitoring seagrass beds}

Selection of an appropriate remote sensing method will obviously depend on the study objectives, budget, availability of hardware and expertise, and study area. However, the following scenarios, in conjunction with Table 3 , should help direct decisions:

Baseline mapping of seagrass beds and their standing crop for general purpose planning

The only significant difference in performance between sensors is their ability to map the extent of seagrass beds. CASI can achieve an accuracy of $87 \%$ (Mumby et al. $1997 \mathrm{c}$ ) but at an estimated cost of ca $£ 81000$ for $15000 \mathrm{~km}^{2}$ (Table 3). Landsat TM will be preferable if a map accuracy of $60 \%$ or less is acceptable or compensated for by the drastic reduction in cost to $\$ 2740$. SPOT XS will only be favoured if the area of interest does not exceed a single SPOT image and low accuracies of $<50 \%$ are tolerable (note: 5 SPOT scenes would be necessary to cover the Caicos Bank).

Aerial photography is the most common remote sensing method for mapping the extent of seagrass beds. Using the results of Sheppard et al. (1995) in Anguilla for comparison (Table 3), 1:10000 colour aerial photography permits seagrass mapping with a slightly greater accuracy than satellite imagery but a significantly poorer accuracy than CASI (Mumby et al. 1997 d). On the premise that quotes for acquiring new aerial photography and CASI imagery of the Caicos Bank apply elsewhere, CASI would be considerably more cost-effective than aerial photography for mapping seagrass (Table 3 ). However, since aerial photography is the standard medium for a variety of applications such as land-use mapping, the cost of data acquisition may be shared between users or avoided entirely. Under these circumstances aerial photography is a cost-effective means of mapping the extent of seagrass beds.

Table 3. Cost and accuracy considerations for mapping seagrass beds with satellite and airborne sensors. Cost (in pounds sterling) of CASI data and aerial photography based on a commercial quote for an area of $15000 \mathrm{~km}^{2}$ of the Caicos Bank. The accuracy of seagrass mapping from aerial photography was calculated from a study of Anguilla using 1:10000 colour photographs (Sheppard et al. 1995). In this example, 1 Landsat TM image and 5 SPOT XS images would be required to map the entire Caicos Bank

\begin{tabular}{|c|c|c|c|c|}
\hline & $\begin{array}{l}\text { Landsat } \\
\text { TM }\end{array}$ & $\begin{array}{l}\text { SPOT } \\
\text { XS }\end{array}$ & CASI & $\begin{array}{c}\text { Aerial } \\
\text { photography }\end{array}$ \\
\hline Accuracy of map $(\%)$ & $<60$ & $<50$ & $<90$ & $<70$ \\
\hline Coverage per scene $(\mathrm{km})$ & $185 \times 185$ & $60 \times 60$ & Variable & Variable \\
\hline Cost $\left(£ \mathrm{~km}^{-2}\right.$ scene $\left.^{-1}\right)$ & 0.08 & 0.47 & 5.40 & 10.70 \\
\hline Cost to map Caicos Bank (E) & 2740 & 8460 & 81000 & 160500 \\
\hline
\end{tabular}


Monitoring change in seagrass boundaries and standing crop

SPOT XS and Landsat TM imagery date back to the mid-1980s and can be used to assess seagrass dynamics over long periods. Whilst the pixel dimensions of these sensors are 20 and $30 \mathrm{~m}$ respectively, neither sensor is likely to be sensitive to changes in seagrass distribution unless the change constitutes several pixels. This insensitivity is partly due to the geometric location of imagery which (in this case) had a root mean square error of 1 pixel width. Added to this is the uncertainty of correctly classifying a pixel as seagrass-particularly at the edge of a seagrass bed where spectral confusion with neighbouring habitats is greatest. Under these circumstances, it is arguable whether remote sensing would be required to measure such extensive changes in cover (i.e. local observations may suffice).

CASI is the only remote sensing method assessed in this study which has the capability to monitor small scale $(-10 \mathrm{~m})$ dynamics of seagrass accurately. Although its ability to predict standing crop is similar to that of sensors currently mounted on satellites, it takes measurements at much finer spatial scales $(1 \mathrm{~m}$ versus 20 to $30 \mathrm{~m}$ ). It follows that seagrass dynamics can be examined in much greater detail (see Fig. 6). The underlying caveat for these conclusions is a requirement for good geometric correction. Ideally, imagery should be registered to charts and flown with an aircraft-mounted differential global positioning system.

The accuracy with which standing crop can be predicted from scanned or visually-interpreted aerial photographs is unknown and, therefore, the relative costeffectiveness of aerial photography and CASI for mapping seagrass standing crop is not clear. While this issue needs to be addressed by further research, the intuitive outcome would favour CASI because CASI has a high spectral resolution (up to 21 spectral bands) and a high radiometric resolution (12-bit digital data compared to an analogue print), and fluctuations in solar irradiance, which can confound the spectra of habitats within a single seagrass bed, can be corrected in CASI data but not in aerial photographs.

The order of magnitude of $95 \%$ CLs was found to be similar for remote sensing and destructive quadrat sampling of seagrass standing crop. This result was surprising given that quadrat sampling is a more accurate technique. However, in terms of estimating mean standing crop, the superior accuracy of quadrats is offset against their size. The statistical population mean of standing crop is estimated from samples of quadrats whereas remote sensing measures the entire population, albeit less accurately.
In a monitoring context, remote sensing will augment a site-specific field monitoring programme by providing a much-needed spatial dimension (Fig. 6). The spatial dimension provides a broader understanding of seagrass dynamics and permits measurements to be made at hierarchical spatial scales (O'Neill 1989, Levin 1992). We suggest that the following procedure should be adopted for monitoring seagrass standing crop:

First assessment at time $T$

(1) Calibration curve is used to predict seagrass standing crop in each seagrass pixel (data layer 1; e.g. Fig. 6)

(2) Curves are fitted to the upper and lower 95\% CLs of the calibration curve

(3) $\pm 95 \%$ CL curves are used to assign confidence limits to each pixel (data layers 2 and 3 )

(4) All 3 raster layers are held in a Geographic Information System (GIS)

Second assessment at time $T+1$

(5) Remote sensing and re-calibration are repeated, providing 3 new data layers

Monitoring spatio-temporal change in seagrass standing crop

(6) All 6 data layers are geo-referenced within a GIS

(7) $95 \%$ CLs between times $T$ and $T+1$ are compared and non-overlapping portions reveal the location and extent of significant changes in 2 dimensions

(8) A final GIS layer is created showing the magnitude and direction of significant changes

\section{CONCLUSIONS}

Given appropriate processing methods and clear water, the digital airborne remote sensing sensor, CASI, can map seagrass boundaries and standing crop to a depth of approximately $10 \mathrm{~m}$. Such maps can be used to examine spatial issues in seagrass ecology, such as the determination of scales of heterogeneity and the description of biomass pattern. In addition, remote sensing provides a spatial perspective to monitoring programmes which will strongly augment the more accurate point measures of change derived from quadrat sampling. The satellite sensors Landsat TM and SPOT XS can map seagrass standing crop at broader spatial scales but extensive field data are required to verify the boundaries of seagrass habitats prior to predicting standing crop.

Acknowledgements. This research was funded by the Environment Research Programme of the Department for International Development. Seagrass studies were also funded by NERC grant number GR9/02233 to C.D.C. and T. Malthus. We are very grateful to the Turks and Caicos Islands' Ministry of Natural Resources for their logistical assistance during our field- 
work, and in particular to C. Hall, C. Ninnes, P. Medley, P. Seymore and J. Ewing. Herb Ripley and the staff of Ariel Geomatics Incorporated are thanked for their dedication to the CASI component. Angie Ellis is acknowledged for her untiring assistance in the field. The School for Field Studies is also thanked for logistical support. The authors also thank Coomaren Vencatasawmy for his statistical advice. Robert Virnstein and 3 anonymous referees are thanked for their comments, which improved an earlier version of this manuscript.

\section{LITERATURE CITED}

Armstrong RA (1993) Remote sensing of submerged vegetation - canopies for biomass estimation. Int J Remote Sens 14:10-16

Bradley E, Tibshirani RJ (1993) An introduction to the bootstrap. Monographs on statistics and applied probability 57 Chapman and Hall, New York

Clark CD, Ripley HT, Green EP, Edwards AJ, Mumby PJ (1997) Mapping and measurement of tropical coastal environments with hyperspectral and high spatial resolution data. Int J Remote Sens 18:237-242

Cuq F (1993) Remote sensing of sea and surface features in the area of Golfe d'Arguin, Mauritania. Hydrobiologica 258:33-40

Dennison WC, Orth RJ, Moore KA, Stevenson JC, Carter C, Kollar S, Bergstrom PW, Batiuk RA (1993) Assessing water quality with submersed aquatic vegetation: habitat requirements as barometers of Chesapeake Bay health BioSci 43:86-94

Downing JA, Anderson MR (1985) Estimating the standing biomass of aquatic macrophytes. Can J Fish Aquat Sci 42 : $1860-1869$

Green EP, Mumby PJ, Clark CD, Edwards AJ, Ellis AC (1997a) A comparison between satellite and airborne multispectral data for the assessment of mangrove areas in the Eastern Caribbean. Proc 4th Int Conf Remote Sensing Marine \& Coastal Environ, Orlando, March 1997, I. Environmental Research Institute of Michigan, Ann Arbor, p 168-176

Green EP, Mumby PJ, Edwards AJ, Clark CD (1996) A review of remote sensing for the assessment and management of tropical coastal resources. Coast Manage 24:1-40

Green EP, Mumby PJ, Ellis AC, Edwards AJ, Clark CD (1997b) The assessment of mangrove areas using high resolution multispectral airborne imagery (CASI). J Coast Res (in press)

Ferguson RL, Wood LL, Graham DB (1993) Monitoring spatial change in seagrass habitat with aerial photography. Photogramm Eng Remote Sens 59:1033-1038

Jernakoff P, Hick P (1994) Spectral measurements of marine habitat: simultaneous field measurements and CASI data. Proc 7 th Australasian Remote Sensing Conf, Melbourne, Australia,p 706-713

Kirkman H (1996) Baseline and monitoring methods for seagrass meadows. J Environ Manage 47:191-201

Kirkman H, Olive L, Digby B (1988) Mapping of underwater seagrass meadows. Proc Symp on Remote Sensing in the Coastal Zone. Department of Geographic Information. Brisbane, VA.2.1-VA.2.9

Levin SA (1992) The problem of pattern and scale in ecology. Ecology 73:1943-1967

Luczkovich JJ, Wagner TW, Michalek JL, Stoffle RW (1993) Discrimination of coral reefs, seagrass meadows, and sand bottom types from space: a Dominican Republic case study. Photogramm Eng Remote Sens 59:385-389

Lyzenga DR (1978) Passive remote sensing techniques for mapping water depth and bottom features. Appl Optics
$17: 379-383$

Lyzenga DR (1981) Remote sensing of bottom reflectance and water attenuation parameters in shallow water using aircraft and Landsat data. Int J Remote Sens 2:71-82

Mumby PJ, Clark CD, Green EP, Edwards AJ (1997a) The practical benefits of water column correction and contextual editing for mapping coral reefs. Int J Remote Sens (in press)

Mumby PJ, Edwards AJ, Green EP, Anderson CW, Ellis AC, Clark CD (1997b) A visual assessment technique for estimating seagrass standing crop. Aquat Conserv: Mar Freshwat Ecosys (in press)

Mumby PJ, Green EP, Clark CD, Edwards AJ (1997c) High resolution airborne remote sensing of coral reefs. Coral Reefs (in press)

Mumby PJ, Green EP, Edwards AJ, Clark CD (1997d) Coral reef habitat mapping: how much detail can remote sensing provide? Mar Biol (in press)

Norris JG, Wyllie-Echeverna S, Mumford T, Bailey A, Turner $\mathrm{T}$ (in press) Estimating basal area coverage of subtidal seagrass beds using underwater videography. Aquat Bot

O'Neill RV (1989) Perspectives in hierarchy and scale. In: Roughgarden J, May RM, Levin SA (eds) Perspectives in ecological theory. Princeton Unıv Press, Princeton, NJ, p $140-156$

Phillips RC, McRoy CP (1990) Seagrass research methods. Monographs on oceanographic methodology 9. UNESCO. Paris

Plummer SE, Malthus TJ, Clark CD (1997) Adaptation of a canopy reflectance model for sub-aqueous vegetation: definition and sensitivity analysis. Proc 4 th Int Conf Remote Sensing for Marine and Coastal Environments, Orlando, March 1997, I. Environmental Research Institute of Michigan, Ann Arbor, p 149-157

Price JC (1987) Calibration of satellite radiometers and the comparison of vegetation indices. Remote Sens Environ $21: 15-27$

Robblee MB, Barber TR, Carlson Ji PR, Durako MJ, Fourqurean JW, Muehlstein LK, Porter D, Yarbro LA, Zieman RT, Zieman JC (1991) Mass mortality of the tropical seagrass Thalassia testudinum in Florida Bay (USA). Mar Ecol Prog Ser 71:297-299

Sabol B, McCarthy E, Rocha K (1997) Hydroacoustic basis for detection and characterisation of eelgrass (Zostera marina). Proc 4th Int Conf Remote Sensing Marine Coastal Environ, I. Environmental Research Institute of Michigan, Ann Arbor, p 679-693

Savastano KJ, Faller KH, Iverson RL (1984) Estimating vegetation coverage in St. Joseph Bay, Florida with an airborne multispectral scanner. Photogramm Eng Remote Sens 50 : $1159-1170$

Sheppard CRC, Matheson K, Bythell JC, Murphy P, Blair Myers C, Blake B (1995) Habitat mapping in the Caribbean for management and conservation: use and assessment of aerial photography. Aquat Conserv: Mar Freshwat Ecosys 5:277-298

Tanre D, Deroo C, Dahaut P, Herman M, Morcrette JJ (1990) Description of a computer code to simulate the satellite signal in the solar spectrum: the $5 \mathrm{~S}$ code. Int $\mathrm{J}$ Remote Sens 11:659-668

Trumble Navigation Ltd (1993) GPS Prolite. Survey and mapping division, 645 North Mary Avenue, Sunnyvale, CA

Zainal AJM, Dalby DH, Robinson IS (1993) Monitoring marine ecological changes on the east coast of Bahrain with Landsat TM. Photogramm Eng Remote Sens 59:415-421

Zar JH (1996) Biostatistical analysis. Prentice Hall Inc, Englewood Cliffs, NJ

Submitted: June 9, 1997; Accepted: September 29, 1997

Proofs received from author(s): November 5, 1997 